\title{
Primary Care implementation of Germ Defence, a digital behaviour change intervention to improve household infection control during the COVID-19 pandemic: A structured summary of a study protocol for a randomised controlled trial
}

Jeremy Horwood ${ }^{1,2,3^{*}}$ (D), Melanie Chalder ${ }^{2}$, Ben Ainsworth ${ }^{4}$, James Denison-Day ${ }^{5}$, Frank de Vocht ${ }^{1,2}$, Martha M. C. Elwenspoek ${ }^{1,2}$, Pippa Craggs ${ }^{1}$, Rachel Denholm ${ }^{1,2}$, Jonathan Sterne ${ }^{2}$, Cathy Rice ${ }^{6}$, Sascha Miller ${ }^{5}$, Beth Stuart ${ }^{7}$, Paul Little', Michael Moore ${ }^{7}$, Merlin Willcox ${ }^{7}$, John Macleod ${ }^{1,2,3}$, Martin Gullford ${ }^{8}$, Kate Morton', Lauren Towler ${ }^{5}$, Nick Francis ${ }^{7}$, Richard Amlôt ${ }^{9}$ and Lucy Yardley ${ }^{1,2,3,10}$

\footnotetext{
Abstract

Objectives: To examine the effectiveness of randomising dissemination of the Germ Defence behaviour change website via GP practices across England UK.
}

Trial design: A two-arm (1:1 ratio) cluster randomised controlled trial implementing Germ Defence via GP practices compared with usual care.

Participants: Setting: All Primary care GP practices in England. Participants: All patients aged 16 years and over who were granted access by participating GP practices.

\footnotetext{
* Correspondence: j.horwood@bristol.ac.uk

${ }^{1}$ National Institute for Health Research, Applied Research Collaboration West (NIHR ARC West) University Hospitals Bristol and Weston NHS Foundation Trust, 9th Floor, Whitefriars, Lewins Mead, Bristol BS1 2NT, UK

${ }^{2}$ Centre for Academic Primary Care (CAPC), Bristol Medical School, Population Health Sciences, University of Bristol, Canynge Hall, 39 Whatley Road, Bristol BS8 2PS, UK

Full list of author information is available at the end of the article
}

C C The Author(s). 2021 Open Access This article is licensed under a Creative Commons Attribution 4.0 International License, which permits use, sharing, adaptation, distribution and reproduction in any medium or format, as long as you give appropriate credit to the original author(s) and the source, provide a link to the Creative Commons licence, and indicate if changes were made. The images or other third party material in this article are included in the article's Creative Commons licence, unless indicated otherwise in a credit line to the material. If material is not included in the article's Creative Commons licence and your intended use is not permitted by statutory regulation or exceeds the permitted use, you will need to obtain permission directly from the copyright holder. To view a copy of this licence, visit http://creativecommons.org/licenses/by/4.0/ The Creative Commons Public Domain Dedication waiver (http://creativecommons.org/publicdomain/zero/1.0/) applies to the data made available in this article, unless otherwise stated in a credit line to the data. 
(Continued from previous page)

Intervention and comparator: Intervention: We will ask staff at GP practices randomised to the intervention arm to share the weblink to Germ Defence with all adult patients registered at their practice during the 4-month trial implementation period and care will otherwise follow current standard management. Germ Defence is an interactive website (http://GermDefence.org/) employing behaviour change techniques and practical advice on how to reduce the spread of infection in the home. The coronavirus version of Germ Defence helps people understand what measures to take and when to take them to avoid infection. This includes hand washing, avoiding sharing rooms and surfaces, dealing with deliveries and ventilating rooms. Using behaviour change techniques, it helps users think through and adopt better home hygiene habits and find ways to solve any barriers, providing personalised goal setting and tailored advice that fits users' personal circumstances and problem solving to overcome barriers.

Comparator: Patients at GP practices randomised to the usual care arm will receive current standard management for the 4-month trial period after which we will ask staff to share the link to Germ Defence with all adult patients registered at their practice.

Main outcomes: The primary outcome is the effects of implementing Germ Defence on prevalence of all respiratory tract infection diagnoses during the 4-month trial implementation period.

The secondary outcomes are:

1) incidence of COVID-19 diagnoses

2) incidence of COVID-19 symptom presentation

3) incidence of gastrointestinal infections

4) number of primary care consultations

5) antibiotic usage

6) hospital admissions

7) uptake of GP practices disseminating Germ Defence to their patients

8) usage of the Germ Defence website by individuals who were granted access by their GP practice

Randomisation: GP practices will be randomised on a 1:1 basis by the independent Bristol Randomised Trials Collaboration (BRTC). Clinical Commission Groups (CCGs) in England will be divided into blocks according to region, and equal numbers in each block will be randomly allocated to intervention or usual care. The randomisation schedule will be generated in Stata statistical software by a statistician not otherwise involved in the enrolment of general practices into the study.

Blinding (masking): The principal investigators, the statistician and study collaborators will remain blinded from the identity of randomised practices until the end of the study.

Numbers to be randomised (sample size): To detect planned effect size (based on PRIMIT trial, Little et al, 2015): 11.1 million respondents from 6822 active GP practices. Assuming 25\% of these GP practices will engage, we will contact all GP practices in England spread across 135 Clinical Commissioning Groups.

Trial status: Protocol version 2.0, dated 13 January 2021. Implementation is ongoing. The implementation period started on 10 November 2020 and will end on 10 March 2021.

Trial registration: This trial was registered in the ISRCTN registry (isrctn.com/ISRCTN14602359) on 12 August 2020.

Full protocol: The full protocol is attached as an additional file, accessible from the Trials website (Additional file 1). In the interest in expediting dissemination of this material, the familiar formatting has been eliminated; this Letter serves as a summary of the key elements of the full protocol.

Keywords: COVID-19, Randomised controlled trial, Protocol, Primary care, Behaviour change, Digital medicine, Infection control, Infectious disease, Protection, Digital health

\section{Supplementary Information}

The online version contains supplementary material available at https://doi. org/10.1186/s13063-021-05188-7.

Additional file 1. Full Study Protocol.

\section{Acknowledgements}

We thank the participating primary care practices and all the clinicians and patients who took part in the study. In addition, we would like to thank Chris Voisey and Margie Berrow CRN West of England and Ed Park from the NIHR CRN Coordinating Centre for their help with management of the study and Chris Metcalfe (University of Bristol) for his assistance with the randomisation of practices. 


\section{Authors' contributions}

$J H, L Y, J M$ conceived the study. JH is the Chief Investigator and led the protocol development. MC, BA, JDD, FdV, ME, PC, RD, JS, CR, SM, BS, PL, MM, $M W$, JM, MG, KM, LT, NF, RA, LY contributed to study design and to development of the protocol. All authors read and approved the final manuscript.

\section{Funding}

This research is funded by UKRI Coronavirus Rapid Response Call (CV220-009) and supported by National Institute for Health Research, Applied Research Collaboration West (NIHR ARC West) and NIHR Health Protection Research Unit (HPRU) in Behavioural Science and Evaluation. UKRI did not play any part in the design of this study, collection, analysis, and interpretation of data, and in writing the manuscript.

\section{Availability of data and materials}

Not applicable.

\section{Declarations}

\section{Ethics approval and consent to participate}

Provisional ethics approval was originally obtained from the NHS Health Research Authority, Yorkshire \& The Humber - Leeds West Research Ethics Committee $(20 / \mathrm{YH} / 0261)$ on 14 August 2020, followed by full approval on 2 September 2020 .

Practices which support the study by promoting the Germ Defence website will, in doing so, have been deemed to have given implicit consent to participate. We will not be seeking individual patent consent as the study requires no deviation from usual care and clinical outcomes will be assessed from anonymised routinely collected NHS patient record data.

\section{Consent for publication}

Not applicable.

\section{Competing interests}

The authors declare that they have no competing interests.

\section{Author details}

'National Institute for Health Research, Applied Research Collaboration West (NIHR ARC West) University Hospitals Bristol and Weston NHS Foundation Trust, 9th Floor, Whitefriars, Lewins Mead, Bristol BS1 2NT, UK. ${ }^{2}$ Centre for Academic Primary Care (CAPC), Bristol Medical School, Population Health Sciences, University of Bristol, Canynge Hall, 39 Whatley Road, Bristol BS8 2PS, UK. ${ }^{3} \mathrm{NIHR}$ Health Protection Research Unit (HPRU) in Behavioural Science and Evaluation, University of Bristol, Bristol, UK. ${ }^{4}$ Department of Psychology, University of Bath, Bath, UK. ${ }^{5}$ School of Psychology, University of Southampton, Southampton, UK. ${ }^{6}$ Stoke Gifford, UK. ${ }^{7}$ Faculty of Medicine, University of Southampton, Southampton, UK. ${ }^{8}$ School of Population Health and Environmental Sciences at King's College London, London, UK. ${ }^{9}$ Behavioural Science Team, Emergency Response Department, Public Health England, Salisbury, UK. ${ }^{10}$ School of Psychological Science, University of Bristol, Bristol, UK.

Received: 10 March 2021 Accepted: 11 March 2021

Published online: 09 April 2021

\section{Publisher's Note}

Springer Nature remains neutral with regard to jurisdictional claims in published maps and institutional affiliations.

Ready to submit your research? Choose BMC and benefit from:

- fast, convenient online submission

- thorough peer review by experienced researchers in your field

- rapid publication on acceptance

- support for research data, including large and complex data types

- gold Open Access which fosters wider collaboration and increased citations

- maximum visibility for your research: over $100 \mathrm{M}$ website views per year

At $\mathrm{BMC}$, research is always in progress.

Learn more biomedcentral.com/submissions 